\title{
Association between ethnicity and obesity with high-density lipoprotein (HDL) function and subclass distribution
}

\author{
Nicholas J. Woudberg ${ }^{1 *}$, Julia H. Goedecke ${ }^{2,3}$, Dee Blackhurst ${ }^{4}$, Miguel Frias ${ }^{5}$, Richard James ${ }^{5}$, Lionel H. Opie \\ and Sandrine Lecour ${ }^{1}$
}

\begin{abstract}
Background: Obesity and low high-density lipoprotein-cholesterol (HDL-C) levels are associated with cardiovascular risk. Surprisingly, despite a greater prevalence of obesity and lower HDL concentrations than white women, black South African women are relatively protected against ischaemic heart disease.

Methods: We investigated whether this apparent discrepancy may be related to different HDL function and subclass distribution in black and white, normal-weight and obese South African women $(n=40)$. HDL functionality was assessed by measuring paraoxonase (PON) activity, platelet activating factor acetylhydrolase (PAF-AH) activity, Oxygen Radical Absorbance Capacity (ORAC) and quantification of the expression of vascular cell adhesion molecule in endothelial cells. PON-1 and PAF-AH expression was determined in isolated HDL and serum using Western blotting. Levels of large, intermediate and small HDL subclasses were measured using the Lipoprint ${ }^{\oplus}$ system.

Results: PON activity was lower in white compared to black women $(0.49 \pm 0.09 \mathrm{U} / \mathrm{L}$ vs $0.78 \pm 0.10 \mathrm{U} / \mathrm{L}, \mathrm{P}<0.05)$, regardless of PON-1 protein levels. Obese black women had lower PAF-AH activity $(9.34 \pm 1.15 \mathrm{U} / \mathrm{L}$ vs $13.89 \pm 1.21 \mathrm{U} / \mathrm{L}, \mathrm{p}$ $<0.05)$ and $\mathrm{HDL}$-associated PAF-AH expression compared to obese white women. Compared to normal-weight women, obese women had lower large HDL, greater intermediate and small HDL; an effect that was more pronounced in white women than black women. There were no differences in antioxidant capacity or anti-inflammatory function across groups.
\end{abstract}

Conclusions: Our data show that both obesity and ethnicity are associated with differences in HDL functionality, while obesity was associated with decreases in large HDL subclass distribution. Measuring HDL functionality and subclass may, therefore, be important factors to consider when assessing cardiovascular risk.

Keywords: High-density lipoprotein, Ethnicity, Obesity, Cardiovascular risk

\section{Background}

Although the leading cause of death in Sub-Saharan Africa remains communicable diseases, the prevalence of ischemic heart disease is increasing and it is predicted to be the leading cause of death in low-income countries by 2030 [1-3]. The changes in standardized health care, progressive changes in socio-economic status

\footnotetext{
* Correspondence: nicholaswoudberg@gmail.com

'Department of Medicine, Hatter Institute for Cardiovascular Research in Africa and South African Medical Research Council Inter-University Cape Heart Group, Faculty of Health Sciences, University of Cape Town, Chris Barnard Building, Anzio Road, Observatory, 7925 Cape Town, Western Cape, South Africa

Full list of author information is available at the end of the article
}

and greater Westernization have raised the burden of preventable cardiovascular diseases (CVD) [4-6]. In addition, nearly $23 \%$ of the worldwide burden of ischaemic heart disease can be attributed to obesity, the prevalence of which has doubled since 1980 [7]. Obesity is associated with insulin resistance, which may increase the risk of type II diabetes and dyslipidaemia, as evidenced by an increase in triglycerides and low-density lipoproteins cholesterol (LDL-C) and a decrease in high-density lipoproteins cholesterol (HDL-C) in these patients [8-11].

Ethnic differences in lipid profiles and CVD risk have been documented, attributed to, in part, genetic, socioeconomic and lifestyle differences $[5,12]$. Black South 
African women and African Americans exhibit protective lipid profiles, characterised by low LDL-C, low triglyceride and low total cholesterol concentrations [13, 14]. In addition, cholesterol-attributable mortality is higher in South African white compared to black populations, with only $1.8 \%$ mortality attributable to 'sub-optimal' cholesterol levels in black populations [15]. It was previously thought that a favourable lipid profile in black populations would also be characterised by higher HDL-C concentrations [16, 17]. However, recent studies conducted in black South African women highlighted a lower or equivalent level of HDL-C than their white counterparts $[6,12,14,18]$.

The Framingham Heart study suggests an inverse relationship between HDL-C levels and cardiovascular risk [19]. However, recent clinical trials aiming to reduce cardiovascular complications by raising HDL-C levels have shown disappointing results $[20,21]$. Elucidation of the complexity of the HDL molecule, has led to a shift from measuring the quantity of HDL-C to assessing the composition, the distribution of individual HDL subclasses and HDL functionality to try to explain the relationship between HDL and cardiovascular risk [22, 23].

The risk of ischemic heart disease in African populations has largely been defined by classical risk factors, including the cholesterol component of HDL. Given the prevailing doubts about the cardiovascular value of HDL-C, the present study used blood collected from a population of black and white, obese and normal-weight South African women, to explore whether ethnicity and obesity may be associated with differences in HDL functionality and subclass distribution.

\section{Methods}

\section{Subjects}

The sample population consisted of 40 normal-weight (Body Mass Index [BMI] $18-24.9 \mathrm{~kg} / \mathrm{m}^{2}$ ) and obese $\left(B M I>30 \mathrm{~kg} / \mathrm{m}^{2}\right)$ self-reported black and white South African women, who had been enrolled for previous studies and described in detail $[18,24]$. Inclusion criteria included (1) age from 18 to 45 years; (2) no known diseases or taking medication for dyslipidemia, diabetes, hypertension, HIV/AIDS or any other metabolic disorders; and (3) not currently pregnant, lactating or postmenopausal. The study was approved by the Research Ethics Committee of the Faculty of Health Sciences of the University of Cape Town.

Basic anthropometric measurements, including height and weight, were taken. Body fat percentage was measured using dual-energy $\mathrm{x}$-ray absorptiometry, while visceral and abdominal subcutaneous adipose tissue were measured using computed tomography as previously described [18]. Fasting serum samples were taken and stored at $-80{ }^{\circ} \mathrm{C}$ prior to use.

\section{Biochemical measurements HDL isolation}

HDL was isolated from $200 \mu \mathrm{l}$ aliquots of serum as follows: Serum samples were added to a mixture containing 1 part 500iu/ml heparin (Mucosal, Fresenius) and 2 parts 1.12 $(\mathrm{mol} / \mathrm{L})$ manganese chloride solution. Samples were centrifuged at $10000 \mathrm{~g}$ for $1 \mathrm{~h}$ at $4{ }^{\circ} \mathrm{C}$. The supernatant was dialysed against phosphate buffered saline (PBS, $\mathrm{pH}$ 7.4) in Spectra/Por 2 RC membrane (12 000-14 000 kDa) (GIC Scientific, 132676) and $200 \mu \mathrm{l}$ aliquots were then dissolved in sodium bromide $(275.5 \mathrm{mg} / \mathrm{ml}$ of supernatant), transferred to thick-wall polycarbonate ultracentrifuge tubes (Beckman, 343775) and centrifuged at $223000 \mathrm{~g}$ for $20 \mathrm{~h}$ at $4{ }^{\circ} \mathrm{C}$ and the upper $70 \mu$ layer was extracted. Purity was confirmed using $12.5 \%$ reducing SDS-polyacrylamide gel electrophoresis (PAGE) stained with Coomassie Blue. The protein concentration of HDL was determined by the modified Lowry method [25]. All samples were analysed in duplicate.

\section{Paraoxonase (PON) activity assay}

Serum samples were diluted 1:10 in phosphate buffer containing $2 \mathrm{mmol} / \mathrm{L} \mathrm{CaCl}_{2}(\mathrm{pH}$ 8). Diluted serum was added to 96-well plates in triplicate and paraoxon-ethyl substrate (Sigma, D9286) was added. Absorbance at $\mathrm{A}_{405}$ was measured at $30 \mathrm{~s}$ intervals over $20 \mathrm{~min}$. One Unit of activity is defined as $1 \mathrm{nmol}$ of substrate hydrolysed per minute.

\section{Platelet Activating Factor Acetylhydrolase (PAF-AH) activity assay}

PAF-AH activity was measured in participant sera using the PAF Acetylhydrolase Assay Kit (Cayman Chemical, 760901). Briefly, serum was added to an equal volume of 5, 5'-dithio-bis-(2-nitrobenzoic acid) (DTNB; Ellman's Reagent) and assay buffer in triplicate into clear 96-well plates. All wells were incubated with 2-thio PAF substrate and absorbance at $\mathrm{A}_{412}$ measured at 1 min time intervals for $20 \mathrm{~min}$. One Unit of activity is defined as $1 \mu \mathrm{mol}$ of substrate hydrolysed per minute.

\section{Western blotting}

Isolated HDL and serum samples from each of the participants were electrophoresed on reducing $12.5 \%$ SDSpolyacrylamide (SDS-PAGE) gels with $1.5 \mu \mathrm{g}$ of $\mathrm{HDL}$ protein or 8 ug of serum loaded per well. Samples were run over three separate gels with control samples repeated in each gel. Blots were transferred onto nitrocellulose membranes (Bio-Rad, 162-0113). Ponceau S staining was used to validate equal loading of wells. Blots were blocked in $5 \%$ low fat milk powder in $0.05 \%$ Tween in Tris-buffered Saline (TTBS, pH 7.5) and incubated overnight in primary mouse anti-PON-1 antibody (1:200) [26] and rabbit anti-PAF-AH (1:400) 
(Cayman Chemical, 160603). Blots were then washed in TTBS and incubated in goat anti-mouse-HRP conjugated secondary antibody (1:5000) (Bio-Rad, 170 6516) and goat anti-rabbit-HRP conjugated secondary antibody (1:2500) (Santa Cruz Biotechnology, sc-2313), respectively for $1 \mathrm{~h}$ at room temperature. Blots were thoroughly washed in TTBS prior to incubation in Amersham TM $\mathrm{ECL}^{\mathrm{m}}$ Western blotting detection reagent (GE Healthcare, RPN2106). Blots were captured in the GeneGnome gel imager. Densitometry of PON-1 and PAF-AH blots was quantified using Quantity one software. PON-1 and PAF$\mathrm{AH}$ relative expression data were corrected for control samples, repeated in each gel.

\section{Oxygen Radical Absorbance Capacity (ORAC) Assay}

Isolated HDL samples were diluted (1:50) in phosphate buffer ( $\mathrm{pH}$ 7.4) prior to analysis for the ORAC assay [27]. Briefly, a trolox standard curve of $0.078 \mathrm{nmol} / \mathrm{L}$ to $10 \mathrm{nmol} / \mathrm{L}$ was prepared. Fluorescein (3', 6' - dihydroxyspiro[isoberyofuran - 1[3H], 9' $[9 \mathrm{H}]$ - xanthen] - 3-one) and AAPH (2,2' - azobis (2-amidinopropane) dihydrochloride) were prepared fresh in phosphate buffer. The working fluorescein solution of fluorescein was $95.7 \mathrm{nmol} /$ $\mathrm{L}$ and AAPH equated to $32.1 \mu \mathrm{mol} / \mathrm{L}$ per well. Fifty $\mu \mathrm{l}$ of trolox standards and HDL samples were added to wells in white 96-well plates (AEC-Amersham) along with AAPH and fluorescein. Fluorescence was measured over time using the Varian Cary Eclipse fluorescence spectrophotometer (Varian Australia Pty Ltd) (Excitation wavelength $485 \mathrm{~nm}$, Emission wavelength $520 \mathrm{~nm}$ ). Data were expressed as Trolox equivalents per volume.

\section{Quantification of HDL anti-inflammatory function}

Human umbilical vein endothelial cells (HUVEC) were purchased from Lonza and were cultured in T75 culture flasks according to supplier specifications. For experimental tests, 30000 cells were seeded into 12-well culture plates and cultured in RPMI-1640 media supplemented with $20 \%$ foetal calf serum (Biochrom BC/S0615), $1 \mathrm{ng} /$ $\mathrm{mL}$ vascular endothelial growth factor (VEGF) (Sigma, V7259) and penicillin/streptomycin (Biowest, L0018). Five hours after seeding, the medium was changed and supplemented with HDL isolated according to optimised protocol at $10 \mu \mathrm{g} / \mathrm{mL}$. Cells were treated with HDL overnight prior to stimulation with $20 \mathrm{ng} / \mathrm{mL}$ murine tumour necrosis factor alpha (TNF- $\alpha$ ) (PeproTech, 315-01A) for $8 \mathrm{~h}$. Cell pellets were harvested and stored in RNA Protect Cell Reagent (Qiagen, 76526) at $-20{ }^{\circ} \mathrm{C}$. RNA was isolated using the RNeasy Micro kit (Qiagen, 74004) and cDNA was synthesised using the High Capacity cDNA Reverse Transcriptase Kit (Life Technologies, 4368814). cDNA was quantified using the Qubit High Sensitivity RNA kit (Qiagen, Q32852) and Qubit Fluorometer (LifeTechnologies). cDNA was amplified for 25 cycles using the RT2 SYBR
Green qPCR kit (Qiagen, 330500) in the RotorGene6000 (Corbit Lifesciences) with the following primers: VCAM-1 (sense), 5'-GAAGATGGTCGTGAT CCTTG-3' and (antisense), 5' -ACTTGACTGTGATCG GCTTC-3'. GAPDH (sense), 5' -CCACCCATGGCAAA TTCCATGGCA-3' and (antisense), 5' -TCTAGACGGC AGGTCAGGTCCACC-3'. Results indicate the mean of at least 3 independent experiments \pm SEM.

\section{Quantification of HDL subclass distribution}

Serum HDL subclass was determined using the Lipoprint $^{\oplus}$ HDL system (Quantimetrix, Redondo Beach, CA) [28]. Briefly, serum $(25 \mu \mathrm{l})$ was mixed with Lipoprint loading gel $(300 \mu \mathrm{l})$, containing Sudan black dye which binds proportionally to the cholesterol present in the sample. The mix was placed onto the upper part of the high resolution $3 \%$ polyacrylamide gel. Photopolymerisation was carried out for $30 \mathrm{~min}$ at room temperature and electrophoresis was performed for $50 \mathrm{~min}$ at $3 \mathrm{~mA}$ per gel tube. After a rest period of $30 \mathrm{~min}$, gel tubes were scanned and analysed using the Lipoware software. The VLDL and LDL remained at the origin [Retention Factor $(\mathrm{Rf})=0.0$ ] while albumin migrated as the leading front $(\mathrm{Rf}=1.0)$. Between these, $10 \mathrm{HDL}$ bands could be detected. HDL-1, HDL-2 and HDL-3 were defined as large HDL; HDL-4, HDL-5, HDL-6 and HDL-7 were defined as intermediate HDL and HDL-8, HDL-9 and HDL-10 were defined as small HDL. Each subclass was quantified and expressed as a percentage of total HDL.

\section{Statistical analysis}

Results are presented as mean \pm standard error of mean (SEM). Two-way analysis of covariance, adjusting for age, was used to compare paraoxonase activity, PAF-AH activity, antioxidant capacity, relative VCAM expression and HDL subclass distribution between normal-weight and obese black and white women. Pearson correlation coefficients were used to explore the relationships between measures of serum lipids, body composition and HDL function and subclass.

\section{Results}

The body composition, lipid profiles and additional physiological data of the participants have been previously published $[18,24]$ and summarised in Table 1. In brief, ethnic differences included lower visceral adipose tissue (VAT) and higher subcutaneous adipose tissue (SAT) in obese black women compared to obese white women. Critically, black women had lower HDL and total cholesterol concentrations than their white counterparts. 
Table 1 Characteristics and serum lipids of participants included in the study

\begin{tabular}{lllll}
\hline & White normal-weight $(n=12)$ & White obese $(n=9)$ & Black normal-weight $(n=8)$ & Black obese $(n=11)$ \\
\hline Age $(\mathrm{yr})$ & $26 \pm 2$ & $34 \pm 2^{\mathrm{B}, \mathrm{C}}$ & $23 \pm 2$ & $27 \pm 2$ \\
BMI $\left(\mathrm{kg} / \mathrm{m}^{2}\right)$ & $22.6 \pm 0.7$ & $33.4 \pm 0.8^{\mathrm{B}, \mathrm{C}}$ & $22.8 \pm 0.9$ & $38.5 \pm 0.7^{\mathrm{D}}$ \\
Fat $(\mathrm{kg})$ & $19.2 \pm 1.4$ & $40.4 \pm 1.6^{\mathrm{C}}$ & $17.1 \pm 1.7$ & $44.9 \pm 1.5^{\mathrm{D}}$ \\
Body fat $(\%)$ & $29.5 \pm 1.4$ & $43.7 \pm 1.6^{\mathrm{C}}$ & $30.0 \pm 1.7$ & $46.7 \pm 1.5^{\mathrm{D}}$ \\
VAT area $\left(\mathrm{cm}^{2}\right)$ & $62.2 \pm 11.3$ & $144.9 \pm 13.1^{\mathrm{B}, \mathrm{C}}$ & $56.9 \pm 13.9$ & $95.6 \pm 11.8^{\mathrm{D}}$ \\
SAT area $\left(\mathrm{cm}^{2}\right)$ & $187.0 \pm 19.1$ & $471.6 \pm 22.0^{\mathrm{B}, \mathrm{C}}$ & $175.2 \pm 23.4$ & $594.2 \pm 19.9^{\mathrm{d}}$ \\
Serum lipids & & & & $1.0 \pm 0.1$ \\
$\quad$ HDL cholesterol (mmol/L) & $1.7 \pm 0.1^{\mathrm{a}}$ & $1.5 \pm 0.1^{\mathrm{B}}$ & $1.3 \pm 0.1$ & $2.1 \pm 0.2$ \\
$\quad$ LDL cholesterol (mmol/L) & $2.0 \pm 0.2$ & $2.5 \pm 0.2$ & $2.1 \pm 0.2$ & $0.8 \pm 0.1$ \\
Triglycerides (mmol/L) & $0.9 \pm 0.1$ & $1.0 \pm 0.1$ & $0.5 \pm 0.1$ & $3.5 \pm 0.2$ \\
Total cholesterol (mmol/L) & $4.1 \pm 0.2$ & $4.6 \pm 0.3^{\mathrm{B}}$ & $3.6 \pm 0.3$ & \\
\hline
\end{tabular}

Values are unadjusted means \pm SEM. All $p$ values are adjusted for age

${ }^{a} p<0.05$ white normal-weight vs black normal-weight

${ }^{\mathrm{B}} p<0.01$ white obese vs black obese

c $p<0.01$ normal-weight vs obese white

${ }^{\mathrm{d}} p<0.05$ and ${ }^{\mathrm{D}} p<0.01$ normal-weight vs obese black

PON activity in normal-weight and obese black and white women

PON activity of normal-weight and obese, black and white women is presented in Fig. 1a. Black women had significantly higher PON activity levels than white women $(0.78 \pm 0.10 \mathrm{U} / \mathrm{L}$ vs $0.49 \pm 0.09 \mathrm{U} / \mathrm{L}, p<0.05)$, with the effect being more pronounced in obese black women compared to obese white women $(0.84 \pm 0.13 \mathrm{U} / \mathrm{L}$ vs $0.45 \pm$ $0.14 \mathrm{U} / \mathrm{L}, p<0.05$ ) (Fig. 1a). Irrespective of ethnicity, PON activity did not differ subject to obesity.

In order to explore whether differences in PON activity levels were simply due to differences in PON-1 protein expression in HDL, Western blotting was performed on isolated HDL and serum. There were no significant differences in HDL-associated PON-1 protein levels between black and white women, nor between normal-weight and obese women (Fig. 1b and c). Similarly, there were no differences in PON-1 serum expression between black and white women, nor between normal-weight and obese women (Fig. 1d and e). Full blot pictures are shown in Additional file 1: Figure S1.

Table 2 shows that PON activity correlated positively with LDL levels in both black and white women $(p<0.05)$, positively with total cholesterol $(p<0.005)$ in black women and negatively with total HDL $(p<0.005)$ in white women.

\section{PAF-AH activity in normal-weight and obese black and white women}

There were no differences in PAF-AH activity between black and white women, however, obese black women had significantly lower PAF-AH activity levels than obese white women $(9.34 \pm 1.15 \mathrm{U} / \mathrm{L}$ vs $13.89 \pm 1.21 \mathrm{U} / \mathrm{L}$, $p<0.05$ ) (Fig. 2a). PAF-AH activity did not differ subject to obesity.
When examining PAF-AH protein expression in isolated HDL, we found that obese black women had significantly lower levels of HDL-associated PAF-AH than obese white women $(5.5 \pm 1.7$ vs $10.9 \pm 1.8$ Arbitrary units, AU, $p<0.05$ ) (Fig. $2 \mathrm{~b}$ and $\mathrm{c}$ ), which corresponds to lower PAF-AH activity $(r=0.54, p<0.005)$. However, there were no differences between black and white obese and normal-weight women in PAF-AH serum expression (Fig. $2 \mathrm{~d}$ and e). Full blots are shown in Additional file 1: Figure S2.

PAF-AH was positively correlated with LDL $(p<0.005)$ and total cholesterol $(p<0.005)$ concentrations in both black and white women (Table 2). In black women only, increased PAF-AH activity was associated with reduced fat mass, SAT and triglyceride concentrations $(p<0.05)$.

\section{Antioxidant capacity and anti-inflammatory function of isolated $\mathrm{HDL}$}

No obesity-related or ethnic differences were observed for the anti-inflammatory function and antioxidant capacity of isolated HDL (Additional file 1: Figures S3 and S4).

\section{HDL subclass distribution in normal-weight and obese black and white women}

Figure 3 shows the distribution of large, intermediate and small HDL subclasses, quantified using the Lipoprint ${ }^{\circledR}$ system. Scans (Fig. 3a) were quantified, producing unique HDL subclass profiles (Fig. 3b-f). HDL subclass distribution was different between obese and normal-weight women with less large HDL $(-10 \%, p<0.05)$ and significantly more intermediate HDL $(+6 \%, p<0.05)$ in the obese compared to the normal-weight women (Fig. 3g), which was largely driven by differences between the normal-weight and obese white women $(43.1 \pm 3.4 \%$ vs 


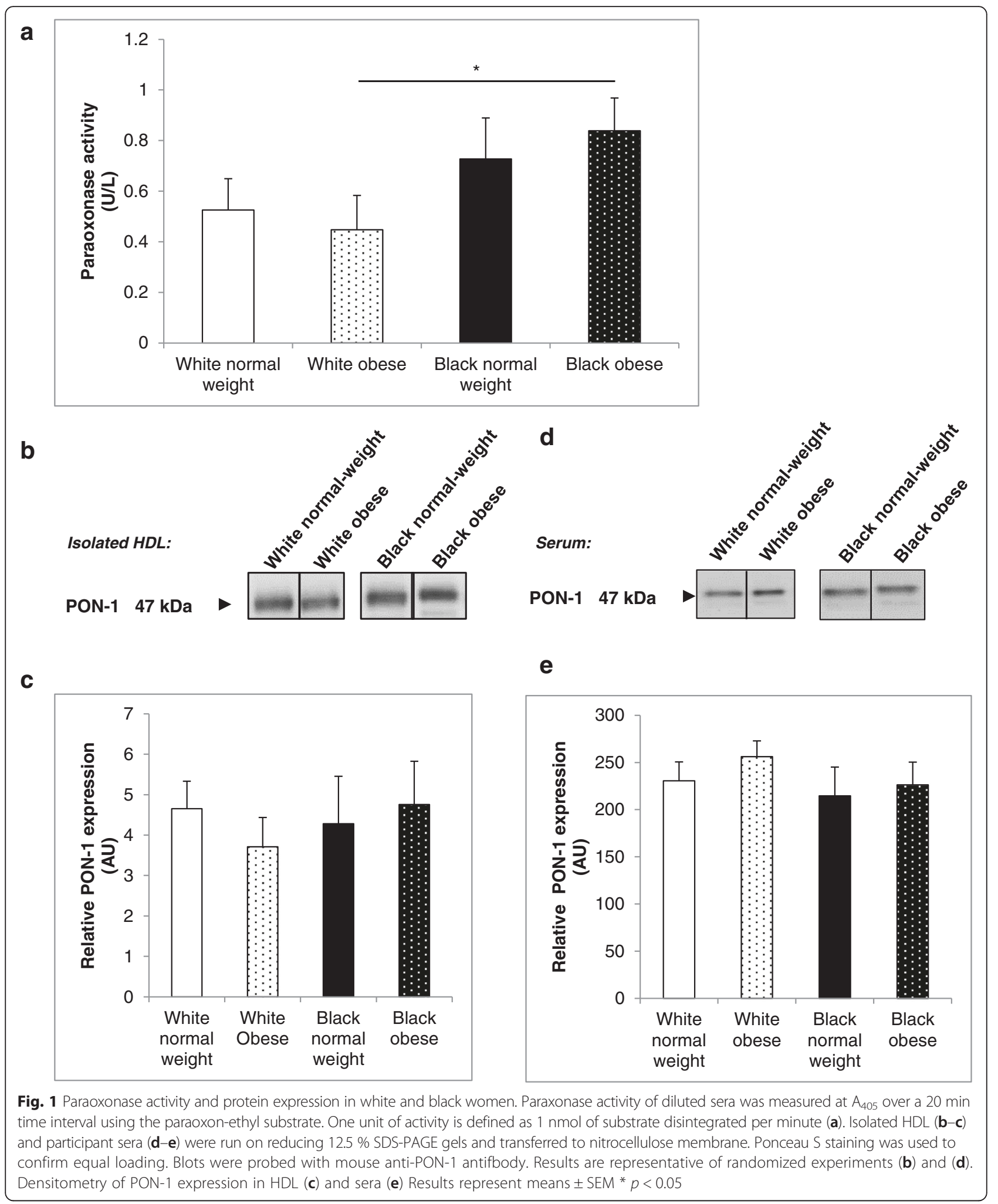

$32.8 \pm 3.8 \%$ for large HDL, $p<0.05$ ) (Fig. 3g). There were no differences in the percentages of small HDL subclasses between groups.
In the white women, the greater proportion of large HDL subclasses was associated with higher BMI, fat mass, VAT and SAT, as well as higher LDL and triglyceride 
Table 2 Associations between HDL functionality measures, HDL subclass, body composition and serum lipids in black and white South African women

\begin{tabular}{|c|c|c|c|c|c|c|c|c|c|c|}
\hline & Ethnicity & $\begin{array}{l}\text { Age } \\
\text { (year) }\end{array}$ & $\begin{array}{l}\mathrm{BMl} \\
\left(\mathrm{kg} / \mathrm{m}^{2}\right)\end{array}$ & $\begin{array}{l}\text { Fat } \\
(\mathrm{kg})\end{array}$ & $\begin{array}{l}\text { VAT } \\
\left(\mathrm{cm}^{2}\right)\end{array}$ & $\begin{array}{l}\text { Total SAT } \\
\left(\mathrm{cm}^{2}\right)\end{array}$ & $\begin{array}{l}\mathrm{HDL} \\
(\mathrm{mmol} / \mathrm{L})\end{array}$ & $\begin{array}{l}\mathrm{LDL} \\
(\mathrm{mmol} / \mathrm{L})\end{array}$ & $\begin{array}{l}\text { Triglycerides } \\
\text { (mmol/L) }\end{array}$ & $\begin{array}{l}\text { Total cholestero } \\
(\mathrm{mmol} / \mathrm{L})\end{array}$ \\
\hline \multirow[t]{2}{*}{ PON Activity } & Black & $r=-0.07$ & $r=0.30$ & $r=0.26$ & $r=0.19$ & $r=0.19$ & $r=0.29$ & $r=0.59^{*}$ & $r=0.13$ & $r=0.66^{* *}$ \\
\hline & White & $r=-0.40$ & $r=0.14$ & $r=0.16$ & $r=-0.25$ & $r=-0.09$ & $r=-0.62^{* * *}$ & $r=0.45^{*}$ & $r=0.21$ & $r=0.28$ \\
\hline \multirow[t]{2}{*}{ PAF-AH activity } & Black & $r=-0.18$ & $r=-0.44$ & $r=-0.47^{*}$ & $r=-0.25$ & $r=-0.48^{*}$ & $r=0.05$ & $r=0.65^{* * *}$ & $r=-0.51^{*}$ & $r=0.53^{*}$ \\
\hline & White & $r=0.02$ & $r=0.42$ & $r=0.39$ & $r=-0.02$ & $r=-0.10$ & $r=-0.37$ & $r=0.85^{* * *}$ & $r=0.22$ & $r=0.80^{* * *}$ \\
\hline \multirow[t]{2}{*}{ Large HDL subclass } & Black & $r=-0.52^{*}$ & $r=-0.32$ & $r=-0.30$ & $r=-0.18$ & $r=-0.31$ & $r=0.69^{* *}$ & $r=0.067$ & $r=-0.19$ & $r=0.25$ \\
\hline & White & $r=-0.31$ & $r=-0.52^{*}$ & $r=-0.48^{*}$ & $r=-0.48^{*}$ & $r=-0.48^{*}$ & $r=0.32$ & $r=-0.49^{*}$ & $r=-0.48^{*}$ & $r=-0.48^{*}$ \\
\hline \multirow{2}{*}{$\begin{array}{l}\text { Intermediate HDL } \\
\text { subclass }\end{array}$} & Black & $r=0.24$ & $r=0.43$ & $r=0.41$ & $r=0.17$ & $r=0.45$ & $r=-0.64^{* * *}$ & $r=0.17$ & $r=-0.15$ & $r=-0.11$ \\
\hline & White & $r=0.40$ & $r=0.46^{*}$ & $r=0.44^{*}$ & $r=0.58^{*}$ & $r=0.51^{*}$ & $r=-0.33$ & $r=0.36$ & $r=0.52^{*}$ & $r=0.34$ \\
\hline \multirow[t]{2}{*}{ Small HDL subclass } & Black & $r=0.52^{*}$ & $r=0.08$ & $r=0.08$ & $r=0.11$ & $r=0.06$ & $r=-0.29$ & $r=-0.24$ & $r=0.42$ & $r=-0.25$ \\
\hline & White & $r=0.20$ & $r=0.52^{*}$ & $r=0.47^{*}$ & $r=0.34$ & $r=0.41$ & $r=-0.27$ & $r=0.55^{* *}$ & $r=0.40$ & $r=0.55^{* *}$ \\
\hline
\end{tabular}

Values are Pearson correlation coefficients

$B M I$ body mass index, VAT visceral adipose tissue, SAT subcutaneous adipose tissue

${ }^{*} p<0.05,{ }^{* *} p<0.01,{ }^{* * *} p<0.005$

concentrations $(p<0.05$, Table 2$)$. In black women, the greater proportion of large HDL was associated with a younger age $(p<0.05)$ and higher HDL-C $(p<0.005)$. Conversely, a greater proportion of intermediate HDL was associated with lower BMI, fat mass, VAT and SAT in white women. A greater proportion of small HDL was associated with increased BMI and fat mass in white women.

\section{Discussion}

In this preliminary study we aimed to examine whether ethnicity and obesity may be associated with differences in HDL functionality and subclass distribution. Our data showed that, despite lower levels of HDL-C, black women had higher PON activity levels compared to white women. In contrast, the activity and protein expression of PAF-AH was lower in obese black compared to obese white women. Obesity was not associated with a difference in the activity of these enzymes, but was associated with a shift in HDL subclass from large to intermediate and small HDL, an effect which was largely driven by differences between normal-weight and obese white women.

The relatively low incidence of myocardial infarction in the South African black population has long been thought to be related to an increase in HDL-C levels in comparison to white populations. However, recent studies provide evidence for lower HDL-C in South African black populations compared South African white populations, despite clear reduced risk of acute myocardial infarction $[6,18]$. Recent research suggests that the quality of HDL, rather than its quantity, may be a more important factor to consider as a cardiovascular risk factor (see review, [23]).

Low serum PON activity levels have been associated with an increased risk for major adverse cardiovascular events (MACE), including myocardial infarction and stroke in an
American study [29]. The novel finding of higher PON activity levels in black women compared to white women, independent of protein expression levels is in contrast to other studies in the USA that found that African Americans had lower or similar PON activity levels than their white counterparts, despite similar HDL-C concentrations [30, 31].

Accordingly, we hypothesise that the low rate of cholesterol-attributable mortality [15], and particularly the low incidence of myocardial infarction in black populations [6] may be explained by higher PON activity levels. However, this hypothesis would need to be tested, as a study in a mixed race South African population found that PON activity was not an accurate predictor of cardiovascular risk [32].

Our data also indicated that increased PON activity in black women was not related to a greater amount of HDL-associated PON-1 protein, which may relate to genetic factors. PON-1 polymorphisms, such as the promotor region small nucleotide polymorphism (SNP) L-55 M, causes a reduction in serum PON activity and is much less frequent in oriental and black populations [33, 34]. Additionally, PON-1 polymorphisms can result in lower activity with PON-1 serum protein levels unchanged [34].

We showed associations between increased PON activity and typical markers of risk, including lower LDL and triglyceride concentrations, which have been reported previously in an American white young adult population [35]. Of interest was a negative correlation between PON activity and HDL-C in white but not black women. Failure to show this association in black women is unexpected because HDL is associated with PON and has been shown in other studies to be negatively correlated with HDL-C $[36,37]$. As PON activity remains consistently high in black women, it is possible that PON activity may be a 

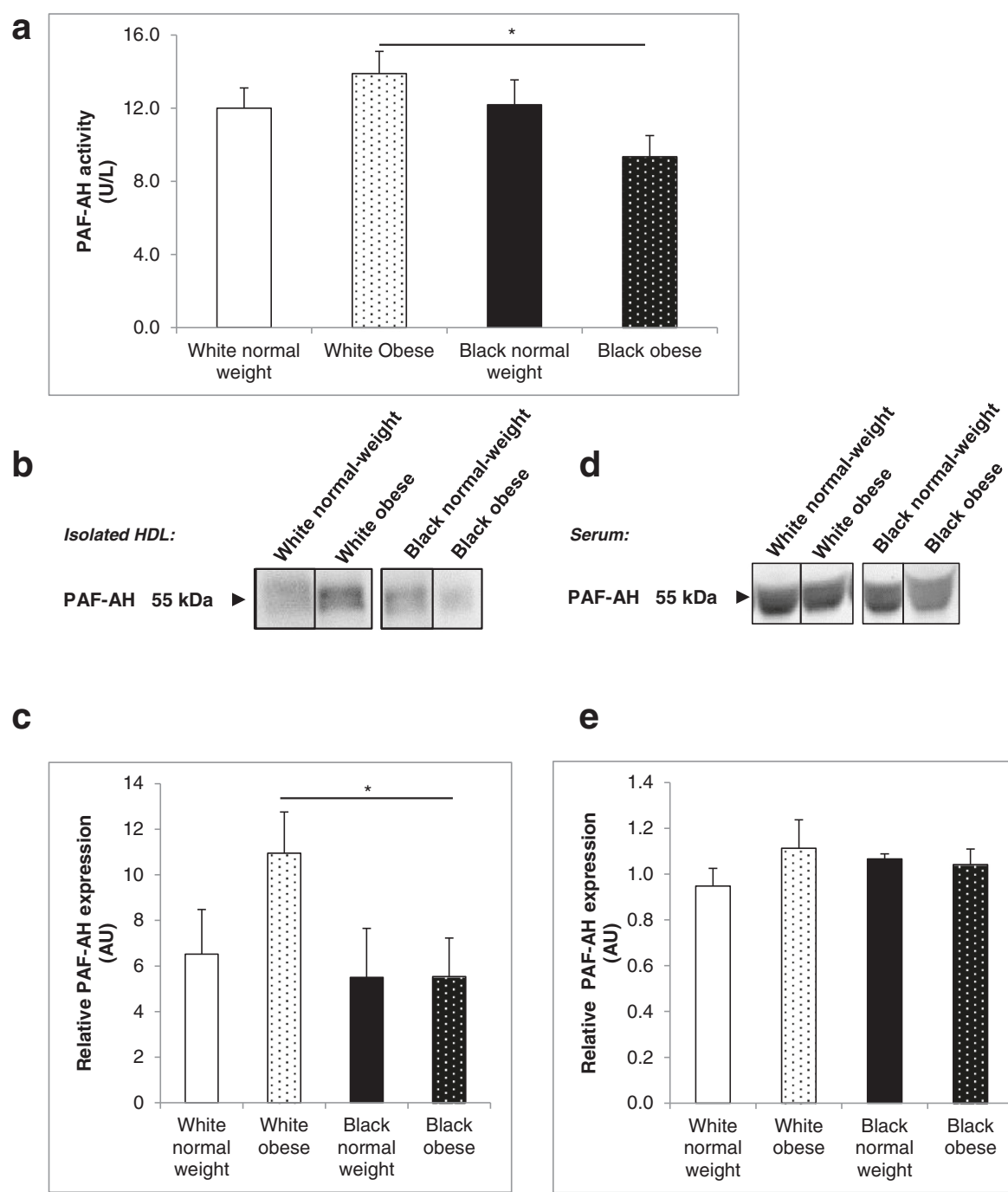

e

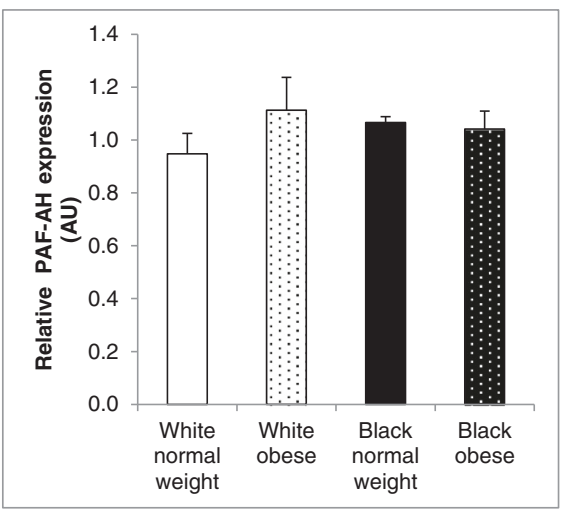

Fig. 2 PAF-AH activity and protein expression in white and black women. PAF-AH activity of diluted sera was measured at $\mathrm{A}_{412}$ over a 20 min time interval using the PAF Acetylhydrolase Assay Kit. One unit of activity is defined as $1 \mu \mathrm{mol}$ of substrate disintegrated per minute (a). Isolated HDL (b-c) and participant sera (d-e) were run on reducing $12.5 \%$ SDS-PAGE gels and transferred to nitrocellulose membrane. Ponceau S staining was used to confirm equal loading. Blots were probed with rabbit anti-PAF-AH antibody. Results are representative of randomized experiments (b) and (d). Densitometry of PAF-AH expression in $\mathrm{HDL}$ (c) and sera (e) Results represent means \pm SEM * $p<0.05$

marker of HDL function in black women, independent of HDL-C levels.

PAF-AH is another HDL-associated enzyme whose primary physiological role is maintenance of PAF metabolism and anti-thrombotic functions [38, 39]. Our data show significantly lower PAF-AH activity in obese black women compared to obese white women. Overall, PAF-AH activity was correlated with PAF-AH expression in HDL while PAF-AH serum expression remained unchanged amongst the groups. Obese black women therefore expressed significantly less HDL-associated PAF-AH than obese white women. Furthermore, reduced PAF-AH activity was associated with increased fat mass and SAT in black women only. PAF-AH is mainly associated with LDL and a smaller proportion with HDL, which translate into different physiological functions of PAF-AH activity [40]. Reduced HDLassociated PAF-AH activity has been shown to be associated with increased risk of cardiovascular disease [41]. Accordingly, our data suggest that reduced HDLassociated PAF-AH activity in obese black women may be associated with a reduction in anti-atherogenic HDL function. However, previous studies have shown that PON activity modulates HDL-associated PAF-AH activity [41]. We, therefore, propose that higher PON activity in obese black women may circumvent reductions in PAF-AH activity. However, further studies are needed to test this hypothesis. 
a

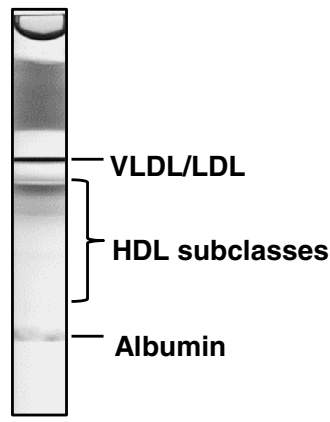

C

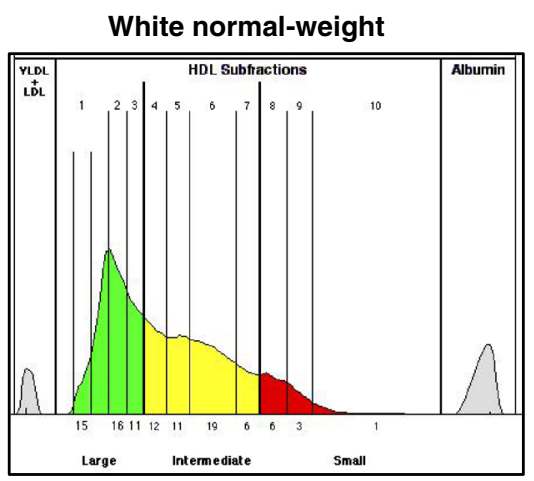

e

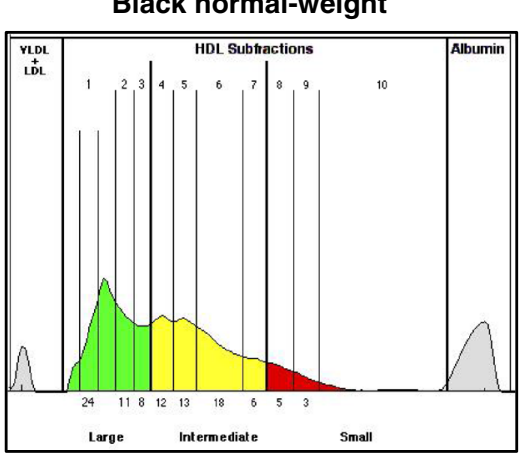

b

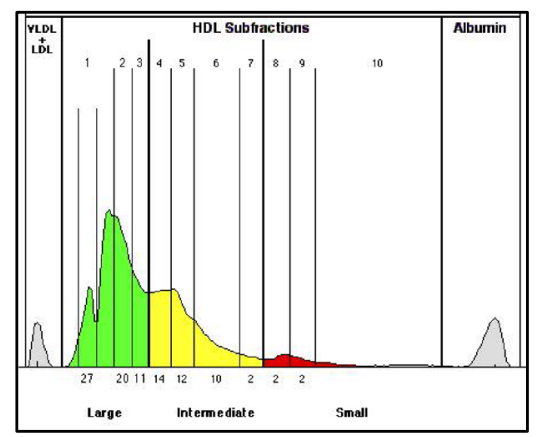

d

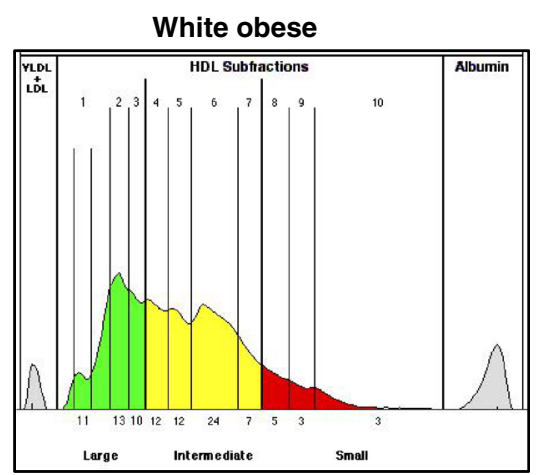

f

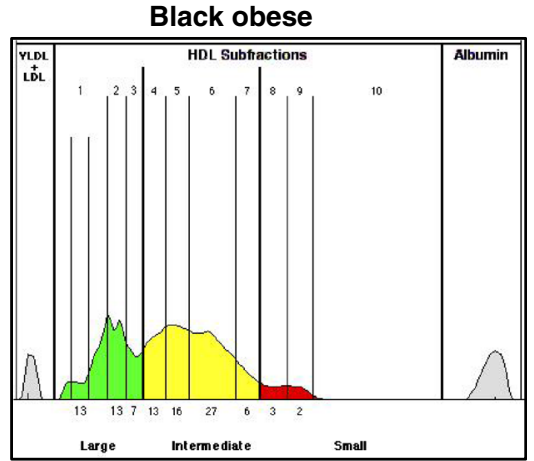

g

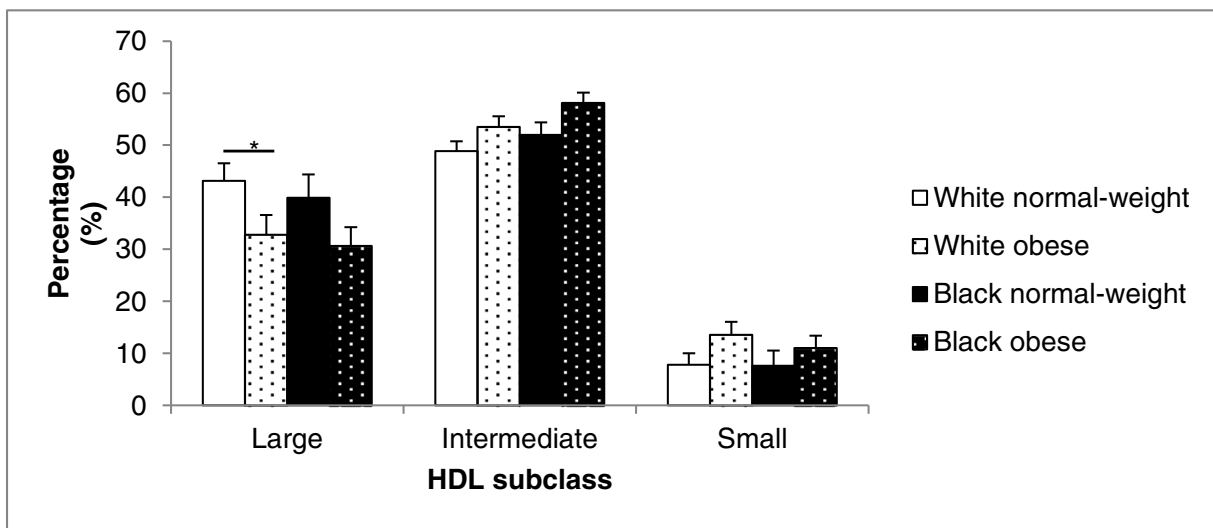

Fig. 3 (See legend on next page.) 
(See figure on previous page.)

Fig. 3 Distribution of HDL subclasses in participant sera. Subject sera was analysed using the Lipoprint ${ }^{\oplus}$ system and analysed using Lipoware software. Representative scan (a) and scan result (b) of Liposure control indicating HDL subclass bands. Representative scan results from white and black obese and normal-weight women (c-f). Percentages of large, intermediate and small HDL subclasses (g). VLDL - Very low density lipoprotein. Results represent means \pm SEM. ${ }^{*} p<0.05$

Surprisingly, despite the findings regarding PON activity, we did not find any significant between group differences in antioxidant capacity of isolated HDL. This was similarly found in a study comparing diet induced weight loss in overweight American participants [42]. We propose that, in the ORAC assay, measurement of total antioxidant capacity may produce different results to a specific antioxidant assay such as PON activity, owing to contributions of additional HDL components. Similarly no differences in the expression of VCAM in HUVEC cells treated with isolated HDL were found. Since HDL has been shown to reduce expression of a number of endothelial adhesion molecules, additional markers would need to be used to further confirm the findings in this study.

To our knowledge, this is the first report of the distribution of HDL subclasses in an African population. In our study a similar profile of HDL subclass distribution was observed between black and white women. However, obesity was associated with reduced large HDL subclasses and concomitant higher intermediate and small subclasses; largely driven by differences between normal-weight and obese white women. In support of this finding, markers of increased adiposity, BMI, fat mass, percentage fat, VAT and SAT correlated with differences in large and intermediate subclasses in white but not black women. This shift has been previously shown in non-African male and female obese populations, where a decrease in average HDL particle size and increased concentrations of smaller HDL subclasses were reported [43-45]. In this case, HDL subclass distribution does not explain changes in functionality related to ethnicity. HDL subclasses were not significantly different between normal-weight and obese black women, while HDL subclasses differed by obesity in white women. A similar trend was observed in LDL subclasses in the same population of women, where differences in LDL subclass in normal-weight and obese women were observed in white but not black women [18].

Longitudinal data on a black South African cohort also indicate that despite increases in weight, HDL-C concentrations remained consistently low in black women [46]. In spite of this, we show that black women display improved HDL antioxidant functionality in comparison to white women, indicating the importance in measurement of HDL quality instead of total HDL cholesterol levels.

\section{Conclusions}

We acknowledge that the small sample size limits the conclusions which can be drawn, however our data indicate that obesity and ethnicity affect HDL functionality and HDL subclass. We, therefore, suggest that future studies examining the association between HDL and cardiovascular risk should focus on examining the role of HDL subclass and functionality. We considered a number of functionality assays in this study, however, additional measures such as reverse cholesterol efflux can be considered in similar studies in the future. Longitudinal studies are required to determine if HDL subclass and function are indeed important risk factors for cardiovascular disease.

\section{Ethics approval}

The study was approved by the Research Ethics Committee of the Faculty of Health Sciences of the University of Cape Town, reference 053/2003.

\section{Consent for publication \\ Not applicable.}

\section{Additional file}

\begin{abstract}
Additional file 1: Figure S1. Paraoxonase protein expression in white and black women. Isolated HDL $(a-c)$ and serum $(d-f)$ from each participant was randomly loaded and run on reducing $12.5 \%$ SDS-PAGE gels and transferred to nitrocellulose membrane. Ponceau $S$ staining was used to confirm equal loading. Blots were probed with mouse anti-PON-1 antibody. WN $=$ White normal-weight. $\mathrm{WO}=$ White obese. $\mathrm{BN}=$ Black normal weight. $\mathrm{BO}=$ Black obese. Figure S2. PAF-AH protein expression in white and black women. Isolated HDL $(\mathrm{a}-\mathrm{c})$ and serum $(\mathrm{d}-\mathrm{f})$ from each participant was randomly loaded and run on reducing $12.5 \%$ SDS-PAGE gels and transferred to nitrocellulose membrane. Ponceau $\mathrm{S}$ staining was used to confirm equal loading. Blots were probed with rabbit anti-PAF-AH antibody. $\mathrm{WN}=$ White normal-weight. $\mathrm{WO}=$ White obese. $\mathrm{BN}=$ Black normal weight. $\mathrm{BO}=$ Black obese. Figure S3. Vascular Cell Adhesion Molecule (VCAM) expression in endothelial cells treated with HDL. HUVEC cells were treated overnight with $10 \mu \mathrm{g} / \mathrm{ml}$ subject HDL. Cells were exposed to $20 \mathrm{ng} / \mathrm{ml}$ tumour necrosis factor (TNF) for $8 \mathrm{~h}$. Cell lysates were harvested and stored in RNAprotect reagent prior to RNA extraction, followed by cDNA synthesis and quantitative real time PCR. Results are presented relative to a no-HDL treatment control. Results are means of 3 independent experiments \pm SEM. Figure S4. Antioxidant capacity of isolated HDL. Isolated subject HDL was diluted in phosphate buffer and measured using the Oxygen Radical Absorbance Capacity (ORAC) assay. (PDF 403 kb)
\end{abstract}

\section{Abbreviations}

BMI: body mass index; DTNB: 5, 5'-dithio-bis-(2-nitrobenzoic acid); HDL-C: highdensity lipoprotein-cholesterol; HUVEC: human umbilical vein endothelial cells; LDL: low-density lipoprotein; PAF-AH: platelet activating factor acetylhydrolase; PON: paraoxonase; SAT: subcutaneous adipose tissue; 
SDS-PAGE: SDS-polyacrylamide; TNF- a: tumour necrosis factor alpha; VAT: visceral adipose tissue; VCAM: vascular cell adhesion molecule; VEGF: vascular endothelial growth factor.

\section{Competing interests}

The authors declare that they have no competing interests.

\section{Authors' contributions}

NJW conducted all research, compiled and analysed data and composed the manuscript. Research was assisted by DB, MF and RJ. SL conceptualized the study. JHG provided samples and together with SL and LO reviewed and assisted with manuscript composition. All authors read and approved the final version

\section{Acknowledgements}

We thank Hendriena Victor from the Division of Exercise Science and Sports Medicine, Department of Human Biology at the University of Cape Town and Jonas Brinck for expert technical assistance with HDL isolation.

\section{Funding}

This study was funded by the National Research Foundation, Medical Research Council, the Swiss South African Joint Research Programme (JRP16) to SL and RWJ and the University of Cape Town.

\section{Author details}

'Department of Medicine, Hatter Institute for Cardiovascular Research in Africa and South African Medical Research Council Inter-University Cape Heart Group, Faculty of Health Sciences, University of Cape Town, Chris Barnard Building, Anzio Road, Observatory, 7925 Cape Town, Western Cape South Africa. ${ }^{2}$ Non-Communicable Disease Research Unit, South African Medical Research Council, Cape Town, South Africa. ${ }^{3}$ Department of Human Biology, University of Cape Town, Cape Town, South Africa. ${ }^{4}$ Division of Chemical Pathology, Department of Pathology, University of Cape Town, Cape Town, South Africa. ${ }^{5}$ Department of Internal Medicine, Faculty of Medicine, University of Geneva, Geneva, Switzerland.

Received: 4 February 2016 Accepted: 2 May 2016

\section{Published online: 11 May 2016}

\section{References}

1. Collaborators G, Europe PMC Funders Group. Global, regional, and national age-sex specific all-cause and cause-specific mortality for 240 causes of death, 1990-2013 : a systematic analysis for the Global Burden of Disease Study 2013. Lancet. 2015:385:117-71.

2. Moran A, Forouzanfar M, Sampson U, Chugh S, Feigin V, Mensah G. The epidemiology of cardiovascular diseases in sub-saharan Africa: The global burden of diseases, injuries and risk factors 2010 study. Prog Cardiovasc Dis. 2013:56:234-9. Elsevier Inc.

3. Mathers CD, Loncar D. Projections of global mortality and burden of disease from 2002 to 2030. PLoS Med. 2006:3:e442.

4. Akinboboye $\mathrm{O}$, Idris $\mathrm{O}$, Akinkugbe $\mathrm{O}$. Trends in coronary artery disease and associated risk factors in sub-Saharan Africans. J Hum Hypertens. 2003;17:381-7.

5. Mayosi BM, Flisher AJ, Lalloo UG, Sitas F, Tollman SM, Bradshaw D. The burden of non-communicable diseases in South Africa. Lancet. 2009;374:934-47.

6. Sliwa K, Lyons JG, Carrington MJ, Lecour S, Marais AD, Raal FJ, et al. Different lipid profiles according to ethnicity in the Heart of Soweto study cohort of de novo presentations of heart disease: cardiovascular topics. Cardiovasc J Afr. 2012;23:389-95.

7. World Health Organization. World Health Organization: Fact sheet: obesity and overweight [Internet]. 2015. Available from: http://www.who.int/ mediacentre/factsheets/fs311/en/. Accessed October 2015.

8. Goff Jr DC. Insulin resistance and adiposity influence lipoprotein size and subclass concentrations. Results from the insulin resistance atherosclerosis study. Metabolism. 2005;54:264-70.

9. Nieves DJ, Cnop M, Retzlaff B, Walden CE, Brunzell JD, Knopp RH, et al. The atherogenic lipoprotein profile associated with obesity and insulin resistance is largely attributable to intra-abdominal fat. Diabetes. 2003;52:172-9.
10. Terry R, Wood P, Haskwell W, Krauss R. Regional adiposity patterns in relation to lipids, lipoprotein cholesterol, and lipoprotein subfraction mass in men. J Clin Endocrinol Metab. 1989;68:191-9.

11. Williams PT, Haskell WL, Vranizan KM, Krauss RM. The associations of high-density lipoprotein subclasses with insulin and glucose levels, physical activity, resting heart rate, and regional adiposity in men with coronary artery disease: The Stanford coronary risk intervention project baseline survey. Metabolism. 1995:44:106-14.

12. Ellman N, Keswell D, Collins M, Tootla M, Goedecke JH. Ethnic differences in the association between lipid metabolism genes and lipid levels in black and white South African women. Atherosclerosis. 2015;240:311-7.

13. Després JP, Couillard C, Gagnon J, Bergeron J, Leon AS, Rao DC, et al Race, visceral adipose tissue, plasma lipids, and lipoprotein lipase activity in men and women: the Health, Risk Factors, Exercise Training, and Genetics (HERITAGE) family study. Arterioscler Thromb Vasc Biol. 2000;20:1932-8

14. Punyadeera C, van der Merwe MT, Crowther NJ, Toman M, Schlaphoff GP, Gray IP. Ethnic differences in lipid metabolism in two groups of obese South African women. J Lipid Res. 2001:42:760-7.

15. Norman R, Bradshaw D, Steyn K, Gaziano T, Collaboration SACRA. Estimating the burden of disease attributable to high cholesterol in South Africa in 2000. S Afr Med J. 2007:97:708-15.

16. Seedat $Y$, Mayet F, Latiff G, Joubert G. Risk factors and coronary heart disease in Durban blacks - the missing links. S Afr Med J. 1992;82:251-6.

17. Steyn K, Goldberg Y, Kotze M, Steyn M, Swanepoel A, Fourie J, et al. Estimation of the prevalence of familial hypercholesterolaemia in a rural Afrikaner community by direct screening for three Afrikaner founder low density lipoprotein receptor gene mutations. Hum Genet. 1996;98:479-84.

18. Goedecke $\mathrm{JH}$, Utzschneider K, Faulenbach MV, Rizzo M, Berneis K, Spinas GA et al. Ethnic differences in serum lipoproteins and their determinants in South African women. Metabolism. 2010;59:1341-50

19. Gordon T, Castelli WP, Hjortland MC, Kannel WB, Dawber TR. High density lipoprotein as a protective factor against coronary heart disease: the Framingham study. Am J Med. 1977;62:707-14.

20. Boden WE, Probstfield JL, Anderson T, Chaitman BR, Desvignes-Nickens P, Koprowicz KM, et al. Niacin in patients with low HDL cholesterol levels receiving intensive statin therapy. NEJM. 2011;365:2255-67.

21. Schwartz GG, Olsson AG, Abt M, Ballantyne CM, Barter PJ, Brumm J, et al. Effects of dalcetrapib in patients with a recent acute coronary syndrome. NEJM. 2012;367:2089-99.

22. Santos-Gallego CG. HDL: Quality or quantity? Atherosclerosis. 2015;243:121-3.

23. Rizzo M, Otvos J, Nikolic D, Montalto G, Toth PP, Banach M. Subfractions and subpopulations of HDL: an update. Curr Med Chem. 2014;21:2881-91.

24. Goedecke JH, Dave JA, Faulenbach MV, Utzschneider KM, Lambert EV, West $\mathrm{S}$, et al. Insulin response in relation to insulin sensitivity an appropriate $\beta$-cell response in black South African women. Diabetes Care. 2009;32:860-5.

25. Markwell MAK, Haas SM, Bieber LL, Ne T. A modification of the Lowry procedure to simplify protein determination in membrane and lipoprotein samples. Anal Biochem. 1978:87:206-10.

26. James RW, Brulhart-Meynet M-C, Singh AK, Riederer B, Seidler U, Out R, et al. The scavenger receptor class B, type I is a primary determinant of paraoxonase-1 association with high-density lipoproteins. Arterioscler Thromb Vasc Biol. 2010:30:2121-7.

27. Cao G, Alessio HM, Cutler RG. Oxygen-radical absorbance capacity assay for antioxidants. Free Radic Biol Med. 1993:14:303-11.

28. Filippatos TD, Liberopoulos EN, Kostapanos M, Gazi IF, Papavasiliou EC, Kiortsis DN, et al. The effects of orlistat and fenofibrate, alone or in combination, on high-density lipoprotein subfractions and pre-beta1-HDL levels in obese patients with metabolic syndrome. Diabetes Obes Metab. 2008;10:476-83

29. Tang WHW, Hartiala J, Fan Y, Wu Y, Stewart AFR, Erdmann J, et al. Clinical and genetic association of serum paraoxonase and arylesterase activities with cardiovascular risk. Arterioscler Thromb Vasc Biol. 2012;32:2803-12.

30. Gaillard T, Parthasarathy S, Osei K. HDL Dysfunctionality (Paraoxonase) is worse in nondiabetic, postmenopausal African American than in white women. Diabetes Care. 2011:34:e19.

31. Healy SJ, Osei K, Gaillard T. Comparative study of glucose homeostasis, lipids and lipoproteins, HDL functionality, and cardiometabolic parameters in modestly severely obese African Americans and white Americans with prediabetes: implications for the metabolic paradoxes. Diabetes Care. 2015;38:228-35. 
32. Macharia M, Kengne AP, Blackhurst DM, Erasmus RT, Hoffmann M, Matsha TE. Indices of paraoxonase and oxidative status do not enhance the prediction of subclinical cardiovascular disease in mixed-ancestry South Africans. Oxid Med Cell Longev. 2014;2014:1-10.

33. Mackness M, Mackness B. Human paraoxonase-1 (PON1): Gene structure and expression, promiscuous activities and multiple physiological roles. Gene. 2015;1:12-21. Elsevier B.V.

34. Phuntuwate W, Suthisisang C, Koanantakul B, Mackness MI, Mackness B. Paraoxonase 1 status in the Thai population. J Hum Genet. 2005;50:293-300.

35. Breton CV, Yin F, Wang X, Avol E, Gilliland FD, Araujo JA. HDL anti-oxidant function associates with LDL level in young adults. Atherosclerosis. 2014;232:165-70.

36. Mackness Ml, Abbott C, Arrol S, Durrington PN. The role of high-density lipoprotein and lipid-soluble antioxidant vitamins in inhibiting low-density lipoprotein oxidation. Biochem J. 1993:294:829-34.

37. Razav A, Ani M, Pourfarzam M, Naderi G. Associations between high density lipoprotein mean particle size and serum paraoxonase-1 activity. J Res Med Sci. 2012;17:1020-6.

38. McIntyre TM, Prescott SM, Stafforini DM. The emerging roles of PAF acetylhydrolase. J Lipid Res. 2009;50 Suppl:S255-9.

39. Stafforini D, Mclntyre T, Carter M, Prescott S. Human plasma plateletactivating factor acetylhydrolase. Association with lipoprotein particles and role in the degradation of platelet-activating factor. J Biol Chem. 1987;262:4215-22.

40. Tselepis AD, Chapman MJ. Inflammation, bioactive lipids and atherosclerosis: Potential roles of a lipoprotein-associated phospholipase A2, platelet activating factor-acetylhydrolase. Atheroscler Suppl. 2002;3:57-68.

41. Kakafika Al, Xenofontos S, Tsimihodimos V, Tambaki AP, Lourida ES, Kalaitzidis $R$, et al. The PON1 M55L gene polymorphism is associated with reduced HDL-associated PAF-AH activity. J Lipid Res. 2003;44:1919-26.

42. Aicher BO, Haser EK, Freeman LA, Carnie AV, Stonik JA, Wang X, et al. Diet-induced weight loss in overweight or obese women and changes in high-density lipoprotein levels and function. Obesity. 2012;20:2057-62.

43. James RW, Brulhart-Meynet MC, Lehmann T, Golay A. Lipoprotein distribution and composition in obesity: their association with central adiposity. Int J Obes Relat Metab Disord. 1997;21:1115-20.

44. Magkos F, Mohammed BS, Mittendorfer B. Effect of obesity on the plasma lipoprotein subclass profile in normoglycemic and normolipidemic men and women. Int J Obes (Lond). 2008:32:1655-64.

45. Tian L, Jia L, Fu M, Tian Y, Xu Y, Tian H, et al. Alterations of high density lipoprotein subclasses in obese subjects. Lipids. 2006;41:789-96.

46. Chantler S, Dickie K, Micklesfield LK, Goedecke JH. Longitudinal changes in body fat and its distribution in relation to cardiometabolic risk in black South African women. Metab Syndr Relat Disord. 2015:13(9):381-8.

\section{Submit your next manuscript to BioMed Central and we will help you at every step:}

- We accept pre-submission inquiries

- Our selector tool helps you to find the most relevant journal

- We provide round the clock customer support

- Convenient online submission

- Thorough peer review

- Inclusion in PubMed and all major indexing services

- Maximum visibility for your research

Submit your manuscript at www.biomedcentral.com/submit 